\section{A saúde na escola: análise dos documentos de referência nos quarenta anos de obrigatoriedade dos programas de saúde, 1971-2011*}

\author{
Health in school: an \\ examination of the reference \\ documents for the forty \\ years of compulsory health \\ programs, 1971-2011
}

Paulo Henrique Nico Monteiro

Pesquisador, Laboratório de História da Ciência/ Instituto Butantan.

Av. Vital Brasil, 1500

05503-900 - São Paulo - SP - Brasil

paulo.monteiro@butantan.gov.br

\section{Nelio Bizzo}

Professor, Faculdade de Educação/Universidade de São Paulo; coordenador, Núcleo de Apoio à Pesquisa "Ensino, Divulgação e Epistemologia da Evolução Biológica", Edevo Darwin/

Universidade de São Paulo.

Av. da Universidade, 308

05508-040 - São Paulo - SP - Brasil

bizzo@usp.br

Recebido para publicação em agosto de 2012.

Aprovado para publicação em julho de 2013.
MONTEIRO, Paulo Henrique Nico; BIZZO, Nelio. A saúde na escola: análise dos documentos de referência nos quarenta anos de obrigatoriedade dos programas de saúde, 1971-2011. História, Ciências, Saúde - Manguinhos, Rio de Janeiro, v.22, n.2, abr.-jun. 2015, p.411427.

\section{Resumo}

O tema da saúde é tradicional nos currículos escolares no Brasil, podendo ser visto em materiais didáticos desde o final do século XIX. Definindo como ponto de partida o estabelecimento da obrigatoriedade do desenvolvimento dos programas de saúde em 1971, este artigo analisa alguns documentos oficiais que buscaram traçar diretrizes para a educação em saúde no âmbito escolar quanto à concepção de saúde expressa, aos objetivos a alcançar e ao papel da educação em saúde na formação geral dos alunos. A análise aponta para uma importante carência de referências que orientem o ensino da saúde na escola, assim como para ideias que permanecem inalteradas, a despeito das mudanças sociais e dos avanços teóricos ocorridos no período.

Palavras-chave: saúde; educação e saúde; ensino fundamental; currículo.

\section{Abstract}

Health is a traditional subject in Brazilian school curriculums, and is evident in teaching materials since the end of the nineteenth century. Taking as its starting point the establishment of compulsory development of health programs in 1971, this article aims to examine certain official documents which sought to set out guidelines for health education in schools, as regards the actual conception of health, the objectives to be achieved, and the role of health studies in the general education of pupils. The analysis highlights an important lack of reference points for regulating health education in schools, and points out ideas which have remained unaltered, despite the social changes and theoretical advances that have occurred during the period.

Keywords: health; education and health; basic education; curriculum. 
$\mathrm{O}$ s temas relacionados à saúde humana tradicionalmente fazem parte do cotidiano escolar no Brasil desde os primeiros anos de escolarização, ocupando em alguns momentos grande parte da carga horária de diversas disciplinas e mobilizando diversos atores na escola. Além disso, ações voltadas para a saúde dos estudantes são comumente desenvolvidas nas escolas, a partir do entendimento de que esse espaço tem a potencialidade de atingir grande número de indivíduos e, dado seu caráter educativo, ser efetivo na mudança de comportamentos e hábitos.

Essa relação entre escola e ações de saúde não é recente. Para Collares e Moysés (1985), é a partir do final do século XIX e, principalmente, na primeira metade do XX, que a saúde adentra o ambiente escolar brasileiro de modo a regulamentar e reger algumas ações dentro da escola. Esse movimento se deu fundamentalmente a partir de duas grandes vertentes.

A primeira, referente aos serviços de "saúde escolar", ou "higiene escolar", vinculados à pasta da educação, dizia respeito às ações desenvolvidas a partir do final do século XIX e principalmente após 1910, que, ao assimilar os pressupostos higienistas vigentes à época, tinham como objetivo "promover e vigiar o saneamento do ambiente escolar e a saúde das crianças, criando condições necessárias para a aprendizagem" (Collares, Moysés, 1985, p.13).

Coerentemente com as ações voltadas para a melhoria das condições sanitárias da sociedade desenvolvidas nesse período, sob a perspectiva da "era do germe" (Nunes, 1998), a escola passou a ser considerada um espaço privilegiado para o desenvolvimento de práticas direcionadas à melhoria das condições sanitárias de uma parcela significativa da população, as crianças, com ênfase na higiene, tanto física como dos modos de ser. Sob essa perspectiva, "a prescrição de um elenco de preceitos e práticas a serem institucionalizados no espaço público da escola, pretendendo ordenar a vida dos escolares sob um novo modo de relação com o mundo - a higiene -, constituiu o cerne do discurso nascente da saúde escolar, então higiene escolar" (Lima, 1985, p.54).

Baseada em preceitos originários da área da saúde e a partir de sua racionalidade científica, fundamentada na fisiologia (Lima, 1985), a "saúde escolar" começa a fazer parte do ambiente da escola e passa a definir ações e intervenções durante todo o século XX. Aspectos relacionados à arquitetura escolar, à infraestrutura, à disposição e às especificações do mobiliário, à regulamentação e à orientação nutricional da merenda escolar, aos exames antropométricos e à detecção de possíveis agravos ou deficiências na população escolar faziam parte desse tipo de ação (Lima, 1985).

Esse movimento atinge seu ápice a partir da década de 1950, quando

a grande ação da área da saúde sobre o espaço escolar não se daria mais como uma prescrição de modos de viver, mas sim como uma intervenção direta e violenta no modo de ser da escola quando a merenda escolar iria tomando corpo até chegar à soberania de 'razão de ser' da escola na década de 1970. A merenda devia existir, no discurso oficial, não por ser algo natural em um ambiente onde existem crianças que, por serem crianças, sentem fome. Ela devia existir como atrativo para que a criança pobre, famélica e desnutrida procurasse a escola (Lima, 1985, p.56).

Levada ao extremo, essa perspectiva da "saúde escolar" acaba por transformar o objetivo final da escola, que deixa de ter como função principal o desenvolvimento do processo ensinoaprendizagem e passa a ser vista como espaço privilegiado para o desenvolvimento de ações 
de caráter assistencialista voltadas para a saúde das crianças, sendo esse o propósito final e a razão de ser da instituição escolar. Em outras palavras, explicita-se que o principal atrativo da escola é o acesso à alimentação e não ao conhecimento, algo que trouxe importantes consequências na formação de uma parcela significativa da população e no próprio papel social da instituição escolar.

Paralelamente a esse movimento, a segunda via de entrada da saúde na escola diz respeito à incorporação dos conteúdos relacionados ao tema no currículo escolar, em que conceitos, informações, valores, atitudes e práticas a ele relacionados passam a fazer parte das atividades a serem desenvolvidas em sala de aula. Portanto, além de ordenar o ambiente e algumas práticas escolares, a saúde passa a ser compreendida também como objeto de trabalho dos professores e de estudo e aprendizagem por parte dos alunos.

Comumente, ações que têm por objetivo promover aprendizagens relacionadas à saúde são desenvolvidas a partir de três modelos ou formas. A primeira, e mais frequente, envolve questões vinculadas a temas específicos, em função de campanhas relacionadas ao setor saúde (saúde bucal, vacinação, prevenção de acidentes, combate às drogas, dengue, entre outras) ou aquelas vinculadas às visitas ou a realização de "palestras" por profissionais de saúde na escola. Tais ações, planejadas em função da agenda do setor saúde ou a partir de contatos e demandas pessoais, são caracterizadas por seu caráter pontual e episódico, assim como pela frágil articulação com os conteúdos desenvolvidos em sala de aula e o processo escolar como um todo.

Além desse aspecto pontual, muitas vezes destituído de continuidade, outra característica passível de crítica é que a entrada de profissionais da saúde no ambiente escolar acaba por desprestigiar a ação e o discurso dos profissionais da educação, mais especificamente do professor, em assuntos relativos ao tema - se é preciso que profissionais externos sejam convidados para que atividades específicas sejam desenvolvidas, há o entendimento tácito de que os docentes não são capazes de desenvolver tais conteúdos sem esse auxílio de especialista.

Um segundo modelo diz respeito aos programas de caráter intersetorial que visam articular saúde e educação com vistas ao desenvolvimento na escola de ações de saúde que tenham caráter mais processual e contínuo. Exemplo recente é o Programa Saúde na Escola (PSE) que, vinculado aos ministérios da Educação e da Saúde, tem como objetivo final "contribuir para a formação integral dos estudantes da rede pública de educação básica por meio de ações de prevenção, promoção e atenção à saúde" (Brasil, 2007). Mesmo tendo caráter mais processual e mais orgânico do que a anterior, a essa modalidade prescinde da atuação de profissionais de saúde junto aos alunos para que tais ações sejam desenvolvidas, o que indica que os riscos de deslegitimação do papel do professor permanecem. Além disso, necessita de articulações intersetoriais nem sempre alcançadas com facilidade em função das diferentes agendas de prioridades.

Finalmente, a incorporação da saúde como objeto de trabalho escolar também é realizada a partir da definição de objetivos e conteúdos relacionados ao tema que devem ser desenvolvidos tanto por disciplinas específicas quanto transversalmente ao currículo escolar. Nesse caso, a saúde passa a fazer parte do rol de conteúdos a ser desenvolvido em sala de aula pelos professores. A ocupação desse espaço não é nova, e exemplos podem ser vistos em livros didáticos brasileiros datados do final do século XIX e início do XX (Ferreira, 1894; Milano, 1922), em 
que preceitos de higiene e regras de "boas condutas" voltadas para a saúde ocupavam boa parte do material.

Na medida em que fazem parte do currículo escolar - entendido aqui como um percurso educacional (Sacristán, 1998; Silva, 2003) e como uma construção cultural (Moreira, Silva, 2002) permeada por diversas influências e visões de mundo (Apple, 2002; Arroyo, 2011) a elaboração e o desenvolvimento curricular dependem de decisões sobre os temas que deverão ser abordados em detrimento de outros, seu encadeamento lógico, suas ênfases e, principalmente, sobre os pressupostos ou ideias-chave relacionadas ao processo ensinoaprendizagem e ao próprio objeto a ser estudado.

Por se tratar de um objeto eminentemente complexo (Almeida Filho, 2000, 2011; Castiel, 2007) e que possibilita diversas abordagens e aproximações, o desenvolvimento dos temas relacionados à saúde humana nos currículos escolares pode expressar diferentes concepções do próprio objeto e diferentes compreensões dos fatores que influenciam ou determinam o processo saúde-doença. Esses diversos entendimentos orientam a educação dos temas relacionados à saúde, posto que "espelham diferentes compreensões do mundo, demarcadas por distintas posições político-filosóficas sobre o homem e a sociedade" (Schall, Struchiner, 1999, p.4).

Em outras palavras, dado que parece ser consensual o fato de que temas relacionados à saúde devem fazer parte do cotidiano da escola, de que saúde se está falando? Quais são as concepções de saúde que embasam ou devem embasar o desenvolvimento curricular? Que aspectos devem ser mais enfatizados e qual deve ser o foco de ação dessas ações? Que conteúdos são os mais relevantes?

Nesse sentido, a elaboração de documentos de referência que balizem as decisões curriculares relacionadas ao tema da saúde torna-se fundamental, pois são eles que irão traçar as diretrizes para o desenvolvimento do tema, definir focos e objetivos, influenciar a elaboração de materiais didáticos diversos, orientar a formação de professores e definir a natureza das diversas ações desenvolvidas na escola.

Assim, a análise dos documentos que traçam diretrizes para o ensino de temas relacionados à saúde na escola ao longo das últimas décadas poderá apontar mudanças ocorridas no período, visões hegemônicas que permanecem nesse período, assim como desafios a enfrentar tanto do ponto de vista didático como de produção de conhecimento sobre o tema.

A partir dessa perspectiva, definimos como objetivo deste artigo analisar os documentos de referência para o ensino dos temas relacionados à saúde no ambiente escolar, especialmente aqueles destinados aos anos iniciais de escolarização, desde o estabelecimento da obrigatoriedade da sua inserção curricular no Brasil, por meio dos "programas de saúde", em 1971.

\section{Os documentos legais e as orientações oficiais}

Definimos como marco inicial da análise aqui proposta a promulgação da lei 5.692/71 (Brasil, 1971), conhecida como a Lei de Diretrizes e Bases da Educação de 1971 (LDB), que instituiu que temas da saúde deveriam ser desenvolvidos de maneira compulsória nos currículos escolares de todos os estabelecimentos de ensino do Brasil, por meio dos "programas de saúde". 
A partir da análise de documentos oficiais ou de orientações de abrangência nacional, buscamos investigar quais concepções de saúde embasam a formulação das propostas, qual o caráter das orientações e das ações que deveriam ser desenvolvidas nas escolas, qual a importância dada às dimensões individual e coletiva da saúde e aos diversos determinantes do processo saúde-doença e, principalmente, quais os objetivos educacionais relacionados ao tema no ambiente escolar.

Cabe ressaltar que, percorridos mais de quarenta anos entre a promulgação da LDB de 1971 e os dias atuais, são poucos os documentos com essas características que tratam especificamente do tema da saúde. Destacam-se nesse conjunto dois documentos: o parecer 2.246/74 do antigo Conselho Federal de Educação (Brasil, 1974), de caráter obrigatório, e os Parâmetros Curriculares Nacionais (PCN), ${ }^{1}$ publicados pelo Ministério da Educação (MEC) na década de 1990, de caráter não obrigatório, mas que influenciaram e continuam influenciando o cotidiano em sala de aula. Em função de sua importância e de suas características serão esses documentos os principais, não sendo os únicos, objetos da análise aqui apresentada.

Vale lembrar que entre o final da década de 1980 e início dos anos 1990, momento de redemocratização no Brasil marcado emblematicamente pela promulgação da Constituição Federal em 1988, as disputas e as atenções no campo da educação estavam voltadas para a discussão acerca da necessidade de uma "nova LDB" - promulgada em 1996 (Brasil, 1996) que deveria traçar seus princípios e objetivos da educação no Brasil, reordenar e reorganizar os sistemas de ensino, assim como servir de marco legal e norteador para diretrizes e orientações propostas posteriormente. Justifica-se, portanto, o intervalo relativamente longo entre os documentos apontados como principais para a análise aqui proposta, uma vez que, nesse período, não foram elaborados documentos de amplitude nacional com vistas a definir diretrizes e orientações à inserção do tema da saúde na escola.

Em seu artigo $7^{\circ}$, a LDB de 1971 definia que "será obrigatória a inclusão de educação moral e cívica, educação física, educação artística e programas de saúde nos currículos plenos dos estabelecimentos de primeiro e segundo graus" (Brasil, 1971), com o objetivo de estimular o conhecimento e a prática da saúde básica e da higiene, a fim de "estimular e guiar o desenvolvimento físico e mental da criança e estabelecer nela sólidos hábitos de saúde" (Bagnato, 1990, p.54).

Claramente, a ideia em que se baseia essa formulação é a compreensão de que a escola é um lugar privilegiado para a aquisição ou mudança de hábitos relacionados à saúde, sendo esse o objetivo final e o objeto da ação pedagógica voltada para a saúde no ambiente escolar.

Os "programas de saúde" propostos por essa legislação tiveram suas diretrizes relacionadas à "educação da saúde"2 por meio do parecer 2.246/74, aprovado em agosto de 1974 pelo Conselho Federal de Educação (CFE), atual Conselho Nacional de Educação (Brasil, 1974). Apesar de esse documento ter sido elaborado há quarenta anos e em um contexto político e institucional bastante distinto do atual, sua análise é importante, pois permite perceber que, a despeito das mudanças ocorridas no período e do avanço conceitual no campo da saúde, muito de seu conteúdo exerceu e vem exercendo influência na definição das diretrizes definidas pelos documentos oficiais elaborados posteriormente, além de continuar balizando a definição dos objetivos e dos conteúdos relacionados à saúde na sala de aula. 
Ao assumir como premissa a definição de saúde formulada pela OMS como "completo bem-estar", a relatora do parecer, professora Edília Coelho Garcia, justifica sua escolha do seguinte modo:

A preferência dada à conceituação da OMS prendeu-se não só no desejo de ter o respaldo da autoridade inconteste daquele órgão, mas também porque o enfoque daquela conceituação se faz no indivíduo. Ainda que se possa focalizar a saúde como um estado de equilíbrio ecológico, e possa a educação ser encarada no seu contexto ecológico e ecológico-social, é para o indivíduo e sua ação que ela deve-se dirigir prioritariamente. O objeto e os objetivos do ensino da saúde na escola devem centrar-se no indivíduo e na sua formação e é para esses que se dirigem o interesse e a vocação do educador (Brasil, 1974, p.64-65).

Claramente, o enfoque individual é aquele a ser privilegiado, e, coerentemente, as ques-tões relativas à aquisição de hábitos "saudáveis" - em especial aqueles ligados à higiene do corpo, mas também relacionados a atitudes e comportamentos - são os objetivos a atingir. Esses objetivos valorizam fortemente o aspecto comportamental em detrimento da compreensão dos fatores intervenientes do processo, posto que "enfatizam a criação de hábitos e atitudes e, subsidiariamente, a aquisição de conhecimentos básicos que justificam, alicerçam e tornam compreensíveis, aqueles hábitos e atitudes" (Brasil, 1974, p.68).

Tendo o indivíduo como único foco, desconsideram-se, portanto, todos os aspectos relativos à dimensão coletiva da saúde, tais como o direito à saúde e ao acesso à assistência, as responsabilidades coletivas e institucionais, as condições de vida, o reconhecimento dos aspectos culturais, os determinantes macroeconômicos, as desigualdades sociais, entre outros.

No que tange especificamente às séries iniciais da escolarização formal (primeiro grau à época), o enfoque nos hábitos de higiene fica mais evidenciado porque o parecer define que "nas primeiras séries de primeiro grau [o ensino da saúde] será sempre desenvolvido como atividade, visando principalmente a criação e a manutenção de hábitos de higiene" (Brasil, 1974, p.71).

Além disso, é explicitada a compreensão de que os problemas de saúde são diretamente ligados a esses hábitos e comportamentos, e que cabe ao indivíduo a responsabilidade por sua própria saúde. A saúde é portanto entendida como uma questão de escolha e de responsabilidade estritamente pessoal, a partir de uma visão claramente comportamentalista: "é evidente que o objetivo final da educação da saúde é a aquisição de um comportamento adequado quanto aos problemas de saúde, pois só esse comportamento pode favorecer a conservação e a promoção da saúde" (Brasil, 1974, p.70).

Há que destacar ainda o caráter pragmático e prático desses programas que deveriam ser, segundo o parecer, desenvolvidos muito mais por meio de atividades práticas do que por meio do desenvolvimento de conteúdos específicos. Além disso, os "programas" não deveriam ser necessariamente desenvolvidos em todas as séries do primeiro e segundo graus, e deveriam abarcar diversas áreas do conhecimento, não sendo objeto de nenhuma das disciplinas escolares; aparecem aqui as bases do que futuramente será definido pelos Parâmetros Curriculares Nacionais (Brasil, 1997a, 1997b, 1997c) como o "caráter transversal" do tema. Coerentemente a essa perspectiva, não se exigia nenhum tipo de formação específica do professor ou professores responsáveis pelo desenvolvimento dos referidos "programas". 
Fica evidente a partir dessa análise que, segundo essas diretrizes da década de 1970, as questões relacionadas aos contextos sociais e às condições de vida dos alunos, ou os determinantes coletivos do processo saúde-doença (aspectos culturais, socioeconômicos, de acesso aos bens e serviços etc.), são muito pouco consideradas como foco da educação da saúde.

Aqui fica bastante clara a relação entre as condições sociais e políticas do momento de elaboração dos documentos e o que deve ser ensinado e aprendido nas escolas, e como os objetivos escolares são definidos por conjunturas sociais, ou seja, a relação entre a escola e a sociedade (Saviani, 1995, 2008). Coerentemente com o período em que foi elaborado, quando o país vivia sob um regime ditatorial em que quaisquer manifestações ou questionamentos das condições sociais e políticas vigentes sofriam violenta repressão e cerceamento, não seria um documento concebido por um órgão oficial do Estado que proporia diretrizes que pudessem ir em direção a qualquer tipo de posicionamento crítico frente à realidade ou mesmo fomentassem algum tipo de organização social de caráter reivindicatório.

Outro momento aqui analisado se refere às publicações oficiais voltadas para o desenvolvimento do tema da saúde na escolarização formal na segunda metade da década de 1990, especificamente aquelas elaboradas após a promulgação da lei 9.394/96 - LDB/96 (Brasil, 1996), vigente atualmente e que estabelece as diretrizes e bases da educação nacional.

As Diretrizes Curriculares Nacionais para o Ensino Fundamental, elaboradas na época (Brasil, 1998a), apontam ser a saúde um dos componentes da Base Comum Nacional (BCN) que "deve integrar-se em torno do paradigma curricular" em todas as escolas no Brasil, a fim de "legitimar e qualificar a ação pedagógica na diversidade nacional" (Brasil, 1998a, p.1). A partir dessa definição, a saúde passou não mais a ser vista como um "programa" a ser desenvolvido pelo conjunto das disciplinas e sim como um componente do conjunto de conteúdos que deveriam ser obrigatoriamente desenvolvidos em todas as escolas brasileiras (Brasil, 1998a).

No parecer do Conselho Nacional de Educação (CNE) que estabelece essas diretrizes (Brasil, 1998b), a incorporação da saúde na BCN é justificada em função da afirmação de sua importância na formação integral do aluno a partir da sua relação com a "Vida Cidadã" (Brasil, 1998b). A partir desse pressuposto, o parecer aponta que "as escolas, com suas propostas pedagógicas, estarão contribuindo para um projeto de nação, em aspectos da Vida Cidadã, expressando as questões relacionadas com a Saúde, a Sexualidade, a Vida Familiar e Social, o Meio Ambiente, o Trabalho, a Ciência e a Tecnologia, a Cultura e as Linguagens, [que] se articulem com os conteúdos mínimos das Áreas de Conhecimento" (Brasil, 1998b, p.9).

Nesse momento, portanto, sugere-se o estabelecimento de uma relação intrínseca entre o desenvolvimento do tema da saúde em sala de aula e uma perspectiva de construção da cidadania, o que pode denotar a compreensão da saúde não mais apenas como um conjunto de hábitos a ser desenvolvido, mas sim a partir da ideia de direito de cidadania, havendo uma importante mudança na perspectiva a ser adotada.

No bojo das ações decorrentes da promulgação da LDB de 1996, são publicados em 1997 pelo MEC os PCN, que, mesmo não tendo caráter obrigatório e, em muitos casos, sofrendo severas críticas quanto aos seus conteúdos e perspectivas de ensino - entre essas as realizadas por Mohr (2002) relativas ao tema da saúde -, passaram a exercer importante influência nos currículos escolares e nos materiais de apoio ao trabalho docente, influência que pode ser vista 
até os dias de hoje como, por exemplo, nos critérios de escolha e adoção de livros didáticos por parte dos professores (Lima, Silva, 2010; Carneiro, Santos, Mol, 2005).

Os PCN afirmam a importância do desenvolvimento da temática da saúde quando definem "Ser Humano e Saúde" como um dos blocos temáticos de conteúdos da disciplina como ciências naturais no ensino fundamental (Brasil, 1997a, p.52), assim como ao definirem a saúde como um dos "Temas Transversais" que devem ser desenvolvidos, de maneira transversal ao currículo, pelo conjunto de disciplinas escolares em todos os anos de escolarização (Brasil, 1997b).

No que diz respeito às expectativas gerais relacionadas ao ensino fundamental (EF), os PCN se referem especificamente ao tema saúde na definição de um dos objetivos gerais a alcançar ao final desse ciclo escolar, uma vez que é esperado "que os alunos sejam capazes de conhecer e cuidar do próprio corpo, valorizando e adotando hábitos saudáveis como um dos aspectos básicos da qualidade de vida e agindo com responsabilidade em relação à sua saúde e à saúde coletiva" (Brasil, 1997a, p.5).

Nesse sentido, fica evidente o entendimento da saúde relacionada a um conjunto de hábitos e atitudes, sendo a escola novamente compreendida como espaço privilegiado para seu desenvolvimento. Para tanto, é enfatizada a necessidade da adoção de um posicionamento "responsável" em relação às escolhas que determinam a situação de saúde, o que traz novamente a ideia da saúde a partir das escolhas pessoais.

Quanto à relação entre a área das ciências naturais e a saúde, os PCN apontam que um dos objetivos gerais dessa área para o ensino fundamental é "compreender a saúde como um bem individual e comum que deve ser promovido pela ação coletiva" (Brasil, 1997a, p.31), o que expressa uma perspectiva da saúde entendida como um "bem" e não apenas na sua dimensão individual, mas também coletiva. A partir desse objetivo, define "Ser Humano e Saúde" como um dos "blocos temáticos" da disciplina que têm como função na estruturação curricular da área "sugerir conteúdos, indicando também as perspectivas de abordagem" (Brasil, 1997a, p.34).

Na apresentação desse "bloco temático", o documento afirma que

o equilíbrio dinâmico, característico do corpo humano é chamado de estado de saúde. Pode-se então compreender que o estado de saúde é condicionado por fatores de diversas ordens: físicos, psíquicos e sociais. A falta de um ou mais desses condicionantes da saúde pode ferir o equilíbrio e, como consequência, o corpo adoece .... . O estado de saúde ou de doença decorre da satisfação ou não das necessidades biológicas, afetivas, sociais e culturais, que, embora sejam comuns, apresentam particularidades em cada indivíduo, nas diferentes culturas e fases da vida (Brasil, 1997a, p.39).

Nessa definição importa destacar a concepção de saúde como equilíbrio relacionado a fatores de diversas naturezas. No entanto, a saúde é tratada como um estado, como o estado de "saúde ou de doença", e não um processo (processo saúde-doença). É possível, portanto, dizer que nessa afirmação está subjacente o entendimento da saúde a partir da clássica dicotomia entre o estado saudável e o enfermo ou entre o normal e o patológico (Canguilhem, 2009). A clássica crítica que se faz à ideia de saúde como um estado diz respeito ao fato de que a saúde aparece como algo que é possível alcançar e manter constante, como "se o estado de saúde fosse um estado estável, que, uma vez atingido, pudesse ser mantido" (Dejours, 1986, p.8), desconsiderando sua natureza de processo iminentemente dinâmico. 
Além disso, ao afirmar que a falta de um dos condicionantes pode vir a comprometer esse estado e, por consequência "o corpo adoecer", reafirma essa dicotomia e não considera que tais fatores não possam ser analisados pela sua presença ou ausência. Em outras palavras, como é possível existir falta de condicionantes biológicos, culturais ou sociais? Ou, em que medida pode-se dizer que esses condicionantes aparecem como ausentes ou presentes, pois dependem das necessidades individuais e devem ser analisados em função de sua relação e influência na situação de saúde dos indivíduos e da população?

Visão bastante distinta aparece quando do tratamento da saúde nos volumes dos PCN que tratam do tema como um Tema Transversal (TT) (Brasil, 1997b). Esse aspecto chama a atenção, pois documentos que, pelo menos em tese, deveriam possibilitar articulações curriculares abordam o tema da saúde a partir de perspectivas e concepções bastante distintas e de certo modo antagônicas. Uma explicação possível para essa importante diferença diz respeito ao processo de elaboração dos PCN, no qual equipes distintas foram responsáveis pelos diversos documentos elaborados relativos às disciplinas escolares (e aos TTs). No caso da saúde especificamente, pode-se dizer que tudo indica a falta de momentos de diálogo e articulação entre as equipes de elaboração dos materiais.

No volume de apresentação dos TTs, justifica-se a pertinência da abordagem de determinados assuntos durante o ensino fundamental, "de maneira transversal às disciplinas escolares e sem se constituir como uma disciplina específica" (Brasil, 1997b, p.23), a partir da constatação de que "há questões urgentes que devem necessariamente ser tratadas, como a violência, a saúde, o uso dos recursos naturais, os preconceitos, que não têm sido diretamente contemplados por essas áreas [as disciplinas escolares tradicionalmente constituídas]" (Brasil, 1997b, p.23). A partir dessa premissa, os TTs que deveriam fazer parte das propostas curriculares foram escolhidos a partir de critérios relacionados à urgência social, à abrangência nacional, à possibilidade de ensino e aprendizagem no ensino fundamental e à possibilidade de compreensão da realidade e participação social.

Diferentemente da concepção do parecer relativo aos "programas de saúde" (Brasil, 1974), esse documento, ao afirmar que "não se pode compreender ou transformar a situação [de saúde] de um indivíduo ou de uma comunidade sem levar em conta que ela é produzida nas relações com o meio físico, social e cultural" (Brasil, 1997c, p.65), apresenta uma perspectiva bastante bem alinhada aos pressupostos da Saúde Coletiva, em especial às ideias de que a saúde deve ser entendida como um processo (processo saúde-doença), determinado por condicionantes biológicos e pelos meios físico, socioeconômico e cultural.

Adicionalmente, a ideia de saúde como um direito universal permeia todo o documento, com referências aos princípios de integralidade, equidade e universalidade de acesso, constituintes do Sistema Único de Saúde (SUS) no Brasil. Afirmações como a seguinte explicitam esse pressuposto: "Sua inclusão [da educação para a saúde] no currículo responde a uma forte demanda social, num contexto em que a tradução da proposta constitucional [que afirma ser a saúde um direito do cidadão e um dever do Estado] em prática requer o desenvolvimento da consciência sanitária da população e dos governantes para que o direito à saúde seja encarado como prioridade" (Brasil, 1997c, p.65).

É pertinente lembrar que, a partir da segunda metade da década de 1980, o movimento denominado "Promoção da Saúde" ganha força internacionalmente no campo da saúde, 
principalmente em função da atuação da Organização Mundial da Saúde e de diversas conferências internacionais sobre o tema (WHO, 2009; Buss, Pellegrini Filho, 2007). Ainda nessa década, reflexos desse movimento chegam ao Brasil, influenciando diversas ações no campo da saúde e também da educação (Westphal, 2006), que podem, aliás, ser vistos claramente na base dos $\mathrm{PCNs}$ relativos à saúde.

Fundamentalmente, os PCNs propõem que a saúde, como objeto de educação escolar, seja tratada como uma das principais estratégias para a promoção da saúde, ao afirmar que "na abordagem apresentada, a educação é considerada um dos fatores mais significativos da promoção da saúde" (Brasil 1997c, p.61). A esse respeito, apontam que

a promoção da saúde se faz por meio da educação, da adoção de estilos de vida saudáveis, do desenvolvimento de aptidões e capacidades individuais, da produção de um ambiente saudável. Está estreitamente vinculada, portanto, à eficácia da sociedade em garantir a implantação de políticas públicas voltadas para a qualidade de vida e ao desenvolvimento da capacidade de analisar criticamente a realidade e promover a transformação positiva dos fatores determinantes da condição de saúde (Brasil, 1997c, p.67).

Ficam claros nessa afirmação o entendimento da promoção da saúde como um aspecto relacionado ao indivíduo, pois são enfatizadas expressões como "estilo de vida" e "aptidões e capacidades individuais", mas também o propósito de criar condições para um posicionamento crítico frente à realidade a fim de transformar os determinantes de saúde. Transita, portanto, entre uma visão conservadora, voltada para o indivíduo e suas escolhas, e uma visão progressista da promoção da saúde, que enfatiza as mudanças das condições desfavoráveis à saúde (Czeresnia, 2009), alinhando-se, dessa forma, à própria definição da OMS para o termo (WHO, 1998).

Quanto a esse aspecto, a necessária relação entre as dimensões individual e coletiva da saúde como diretriz para o ensino do tema fica evidente no documento, ao afirmar que "os enfoques segundo os quais a condição de saúde individual é determinada unicamente pela realidade social ou pela ação do poder público, tanto quanto a visão inversa, nem por isso menos determinista, que coloca todo peso no indivíduo, em sua herança genética e em seu empenho pessoal, precisam ser rompidos [nas propostas para o ensino do tema]" (Brasil, 1997c, p.65).

Em função dessa base teórica, um dos focos do documento diz respeito à crítica feita à tradição de desenvolvimento do tema na escola, exposta do seguinte modo, já em sua apresentação: "o ensino de saúde tem sido um desafio para a educação no que se refere à possibilidade de garantir uma aprendizagem efetiva e transformadora de atitudes e hábitos de vida. As experiências mostram que transmitir informações a respeito do funcionamento do corpo e a descrição das doenças, bem como um elenco de hábitos de higiene, não é suficiente para que os alunos desenvolvam atitudes de vida saudável" (Brasil, 1997c, p.61).

Essa crítica se faz mais explicitamente na proposição das diretrizes para o ensino da temática, em que o documento propõe uma diferença entre as expressões "ensinar saúde" e "educar para a saúde", enfatizando a necessidade do desenvolvimento de atitudes e valores favoráveis ao desenvolvimento da saúde como um todo, características, segundo o MEC, da segunda perspectiva de ensino (ou o "educar para a saúde"). 
No primeiro caso (ensinar saúde) o foco é colocado numa formação sobre saúde e na coincidência de conceitos que fundamentou a proposta clássica de inserção dos programas de saúde no escopo da disciplina Ciências Naturais ... . Isso não quer dizer que as informações e a possibilidade de compreender a problemática que envolve as questões de saúde não tenham importância ou que não devam estar presentes no processo de ensinar e aprender para a saúde, mas sim que a educação para a Saúde só será efetivamente contemplada se puder mobilizar as necessárias mudanças na busca de uma vida saudável (Brasil, 1997c, p.69).

Essa diferença de abordagem é justificada pela constatação de que a informação isolada e descontextualizada é pouco efetiva para as mudanças esperadas e que "o 'biologismo' - que valoriza a anatomia e a fisiologia para explicar a saúde e a doença - não dá conta dessa tarefa [de desenvolvimento de atitudes e hábitos favoráveis à saúde]" (Brasil, 1997c, p.69). Vale destacar que o mesmo documento deixa claro que não há a desconsideração dos conteúdos e conceitos das ciências naturais (ou da biologia) na abordagem proposta ao afirmar que "os detalhes relativos a processos fisiológicos ou patológicos ganharão sentido no processo de aprendizagem na medida em que contribuírem para a compreensão das ações de proteção à saúde a eles associadas" (Brasil, 1997c, p.69).

Portanto, a crítica feita pelos PCN não aponta para uma desconsideração dos conteúdos da área, mas chama a atenção para uma abordagem que, segundo os autores do documento, é hegemônica nas ciências naturais que, ao enfatizar a descrição da doença a partir de seus aspectos biológicos, privilegia o discurso acerca da doença e não da saúde. Em outras palavras, a crítica diz respeito à tendência de as discussões sobre a saúde na escola reduzirem o objeto apenas aos seus aspectos biológicos ou, mais radicalmente, à descrição da doença.

Nesse sentido, o aspecto importante a ser ressaltado nos PCN, e na crítica que esses documentos fazem à tradição do ensino dos temas relacionados à saúde, diz respeito à importância da incorporação de discussões acerca dos fatores que extrapolam sua dimensão biológica, sem os desmerecer. Os documentos trazem com bastante ênfase a necessidade da incorporação de conteúdos relacionados aos determinantes sociais do processo saúde-doença, ou seja, seus aspectos de caráter social, cultural, econômico, de condições de vida e moradia, de acesso aos bens e serviços, entre outros no desenvolvimento do tema em sala de aula.

Além disso, estão baseados na ideia da saúde como um direito que, assim como os outros, é passível de reivindicações tanto no que diz respeito à melhoria das condições desfavoráveis, quanto relacionadas ao acesso aos serviços de assistência. Essa perspectiva aparece claramente quando da definição dos objetivos educacionais para o ensino fundamental: "a Educação para a Saúde cumprirá seus objetivos ao conscientizar os alunos para o direito à saúde, sensibilizá-los para a busca permanente da compreensão de seus determinantes e capacitá-los para a utilização de medidas práticas de promoção, proteção e recuperação da saúde ao seu alcance" (Brasil, 1997c, p.71).

Sem dúvida, ao enfatizar esses aspectos, os PCN adotam uma postura que traz um importante avanço no sentido de contribuir para a compreensão da saúde a partir de uma visão ampliada de seus determinantes. Dessa forma, contribuem com a formação dos professores, em especial daqueles que trabalham com os primeiros anos do ensino fundamental que, dada sua formação de caráter generalista, tiveram pouco ou nenhum contato com a perspectiva 
e com o referencial apresentado. Nesse sentido e a despeito das críticas feitas aos PCN, é possível dizer que, no que tange ao ensino dos temas relacionados à saúde, tais documentos podem ser considerados marcos na definição de propostas para o ensino do tema da saúde no ambiente escolar.

Mais recentemente, em função da reorganização do ensino fundamental no Brasil, que passou a ter nove anos, novas diretrizes foram formuladas (Brasil, 2010a). Essas diretrizes definem um conjunto de princípios éticos, políticos e estéticos a serem adotados como norteadores das políticas e das ações pedagógicas das escolas e sistemas de ensino. Entre seus princípios políticos está "o reconhecimento dos direitos e deveres de cidadania, de respeito ao bem comum e à preservação do regime democrático ... da busca da equidade no acesso à educação, à saúde, ao trabalho, aos bens culturais e outros benefícios" (Brasil, 2010a, p.2).

Mesmo não definindo a saúde como componente da BCN - diferentemente, portanto, da legislação de 1998 - e, nesse sentido, não definindo com clareza a importância do desenvolvimento do tema em sala de aula, as atuais diretrizes definem que a saúde deve constar das propostas curriculares, uma vez em que "os componentes curriculares e as áreas de conhecimento devem articular em seus conteúdos, a partir das possibilidades abertas pelos seus referenciais, da abordagem de temas abrangentes e contemporâneos ... Temas como saúde, sexualidade e gênero, vida familiar e social ... devem permear o desenvolvimento dos conteúdos da base nacional comum e da parte diversificada do currículo" (Brasil, 2010a, p.5).

O parecer do Conselho Nacional de Educação (CNE) referente a essas diretrizes (Brasil, 2010b) explicita a dimensão valorativa relaciona à saúde ao afirmar que "a ciência que a escola ensina está impregnada de valores que buscam promover determinadas condutas, atitudes e determinados interesses, como por exemplo, a valorização e preservação do meio ambiente, os cuidados com a saúde, entre outros" (Brasil, 2010b, p.11). Somado a isso, o referido parecer, ao discutir as orientações para a escola de tempo integral, aponta que atividades de promoção da saúde devem fazer parte do conjunto de atividades propostas pelas escolas que adotarem essa modalidade de ensino (Brasil, 2010b).

Quanto à legislação atual, cabe destacar dois aspectos. Primeiramente, o fato de que não existe atualmente nenhum documento oficial que aponte concepções ou perspectivas para o ensino dos temas relacionados à saúde na escola, seja por meio de sua incorporação nas propostas curriculares, seja pelo desenvolvimento de programas e projetos específicos. Os PCN, mesmo tendo sido publicados há mais de 15 anos e não tendo caráter obrigatório, continuam sendo referências importantes tanto para professores quanto para os formuladores e autores de materiais didáticos e de apoio à sala de aula.

Em segundo lugar, não trata a saúde como um tema que deve fazer parte dos currículos escolares, apenas reafirma a importância do desenvolvimento do tema como fundamental para a construção da cidadania e para o desenvolvimento integral do aluno. Adicionalmente, ambos os documentos (diretrizes e parecer) afirmam, de maneira um tanto vaga, ser a "área da saúde" uma das fontes teóricas nas quais as diversas disciplinas escolares se devem apoiar para a definição dos conceitos e dos conteúdos a desenvolver. 


\section{Lacunas, mudanças e permanências}

A partir da análise apresentada, fica claro que, desde o estabelecimento da obrigatoriedade do desenvolvimento dos "programas de saúde", em 1971, apenas dois documentos oficiais de escopo nacional, o parecer 2.246/74 do Conselho Federal da Educação (de caráter obrigatório) e os Parâmetros Curriculares Nacionais (não obrigatórios), procuraram apontar concepções e perspectivas para o desenvolvimento dos temas relacionados à saúde humana no cotidiano escolar em todos os sistemas de ensino da educação básica, podendo ser considerados marcos nessa trajetória. Portanto, mesmo sendo a saúde um tema tradicionalmente desenvolvido desde os anos iniciais na escola e a despeito de sua complexidade e das diversas possibilidades que se anunciam para o seu desenvolvimento em sala de aula, apenas dois documentos oficiais se dispõem a discutir concepções de saúde e traçar as diretrizes para o ensino nas escolas nos últimos quarenta anos.

Esses documentos, como não poderiam deixar de ser, são reflexos dos contextos sociais e políticos nos quais foram elaborados e, nesse sentido, refletem diferentes concepções de saúde e, principalmente, objetivos distintos relacionados à inclusão dos temas de saúde no ambiente escolar. Fica clara a ênfase exclusiva no indivíduo, descontextualizado de seu ambiente, no caso do parecer de 1974, que contrasta com uma perspectiva da saúde como componente da cidadania, como estratégia de promoção da saúde ancorada, portanto, em sua dimensão coletiva e entendida como um direito no caso dos PCN.

Nesse sentido e a despeito das críticas a esse material, é possível dizer que há um importante avanço tanto do ponto de vista conceitual quanto epistemológico e político nas orientações expressas nos PCN, ao afirmar a saúde como direito e determinada por fatores que dizem respeito à construção de condições de vida minimamente dignas.

A falta de um documento atual, de abrangência nacional, que oriente o ensino dos temas da saúde na escola permite afirmar que há uma importante carência de documentos orientadores atuais que incorporem as discussões realizadas no campo da saúde. Dada essa carência, cabe aos professores, muitas vezes sem a formação necessária, a partir de suas concepções individuais e subsidiados por materiais de distintas qualidades, o desenvolvimento de temas com essa complexidade em sala de aula. Nesse sentido, o caráter idiossincrático e pessoal de cada professor acaba por prevalecer nessas atividades.

Outro aspecto a ser apontado é que reflexos das diretrizes traçadas no parecer de 1974 escrito em um contexto político e social bastante distinto - continuam presentes nas orientações elaboradas posteriormente. Primeiramente, destaca-se a compreensão da escola como ambiente propício para o desenvolvimento de hábitos, atitudes e condutas favoráveis à saúde, pressuposto e princípio norteador desse parecer e que permanece em muitas das orientações propostas pelos PCN, que afirmam ser esse um dos objetivos, senão o principal, da educação para a saúde.

Mesmo considerando a importância do trabalho escolar na aquisição e mudança de hábitos, especialmente nos anos iniciais de escolarização, há que levar em conta que os hábitos não são de caráter meramente individual, mas estão relacionados aos contextos e condições de vida dos alunos e suas famílias.

A esse respeito, Bagnato (1990, p.53), já na década de 1990, afirmava que a maneira como o ensino dos temas relacionados à saúde foi desenvolvido a partir dos "programas de saúde" 
"parece pouco influir nos hábitos e atitudes de higiene que as crianças possuem. A família e o meio ambiente influem de maneira mais contundente em tais hábitos e atitudes, quer sejam adequados ou não", chamando a atenção para o fato de que "é importante lembrar que as mudanças de comportamentos relacionados com a higiene e a saúde não são asseguradas só pelo ensino da saúde; elas devem ser acompanhadas por condições adequadas de vida dos alunos e suas famílias e o ensino da saúde deve se dar mais em termos de discutir todas essas questões, contextualizando-as" (p.56).

Ou seja, hábitos e atitudes só poderão ser discutidos e incorporados (na medida do possível) a partir de propostas que estejam baseadas não apenas em prescrições do que "é adequado" ou não, ou que só digam respeito ao conhecimento acerca das doenças, sintomas, riscos e medidas de prevenção. Para que façam sentido, essas discussões devem realizar-se a partir de uma moldura mais ampla, que incorpore questões relacionadas às condições de vida, moradia, acesso aos bens e serviços, componentes culturais, econômicos, políticos etc.

Outro ponto a ser destacado é que permanece a ideia de que o tema da saúde deve ser tratado pelo conjunto de disciplinas. Sendo de responsabilidade de todo o corpo docente, não cabe a nenhuma disciplina ou profissional específico desenvolver esse conteúdo, o que será caracterizado em 1997 pelos PCN com o caráter de transversalidade ao currículo. Cabem aqui alguns questionamentos: Quem são os responsáveis por elaborar, coordenar e desenvolver as propostas que, em tese, devem levar em conta o contexto escolar e de vida dos alunos e de suas famílias? Quais são os conhecimentos necessários aos professores responsáveis por essas propostas? Com base em que conjunto de conceitos e concepções as ações são planejadas? Como articular essas propostas a partir de objetivos e pressupostos comuns? Qual a formação necessária? Quem é a autoridade que fala sobre saúde na escola?

Esse problema não é novo e é apontado como um desafio a ser superado em artigos publicados desde a década de 1980 (Moura, 1980; Lima, 1985; Schall et al., 1987). Segundo Lima (1985), a falta de formação específica para o desenvolvimento do tema na escola já se configurava como um dos aspectos mais preocupantes na proposta dos "programas de saúde", que acabam por ser baseados no "bom senso" dos professores e são, muitas vezes, permeados por concepções equivocadas, prescrições de caráter doutrinário e preconceitos.

Portanto, a ideia de transversalidade presente tanto na proposta da década de 1970 quanto nas atuais, passando pelos PCN, traz dentro de si o desafio da formação docente, algo que parece não ocorrer de maneira a contemplar a complexidade do tema nos cursos tanto de formação inicial quanto continuada de professores. A falta de documentos atuais de caráter oficial e abrangência nacional que minimamente orientem quanto à concepção de saúde que deve basear as propostas e, fundamentalmente, definam com clareza os direitos de aprendizagem a ser garantidos quando do desenvolvimento dos conteúdos relacionados à saúde no ambiente escolar acaba por agravar esse problema.

\section{Considerações finais}

Nos últimos quarenta anos, a saúde passou a ser incorporada mais fortemente ao cotidiano escolar como objeto de aprendizagem dos alunos, a partir da obrigatoriedade do desenvolvimento dos "programas de saúde", tendo como marco a ideia de aquisição de 
um conjunto de hábitos considerados "saudáveis". Pode-se perceber que, ao longo desse período, são poucos os documentos oficiais que apontam perspectivas e definem diretrizes para o desenvolvimento dos temas relacionados à saúde, destacando-se o parecer 2.246/74 do Conselho Federal de Educação e os Parâmetros Curriculares Nacionais.

A análise desses documentos aponta para importantes avanços e mudanças na compreensão da saúde, a partir da incorporação de seus determinantes sociais, da ideia de direito à saúde e da incorporação da dimensão coletiva aos objetivos da educação para a saúde. No entanto, alguns aspectos devem ser encarados como desafios para que a escola se torne, de fato, um local de aprendizagens que propiciem aos alunos condições de compreensão dos diversos fatores que determinam sua situação de saúde, assim como da comunidade em que vive, e possa se posicionar criticamente em relação a essas condições.

É necessário que a ideia de aquisição (ou mudança) de hábitos, por exemplo, não esteja atrelada necessariamente às orientações de caráter prescritivo e muitas vezes doutrinário, algo que é tradicionalmente realizado, especialmente nos anos iniciais do ensino fundamental. Para que haja aprendizagens significativas a esse respeito, é necessário que temas como as condições de vida, as possibilidades e potencialidades de cada indivíduo e comunidade, os costumes e aspectos culturais de cada grupo populacional, os aspectos sociais deletérios ou favoráveis à saúde, entre outros, sejam incorporados como pressupostos que embasem as discussões realizadas na sala de aula e não apenas como exemplos ou fatos isolados.

Essa perspectiva pressupõe que professores e equipe escolar compreendam a saúde a partir de seu conceito ampliado, incorporando aportes teóricos originários da área da Saúde Coletiva, seja em sua formação inicial ou continuada, para que o "bom senso" não seja o principal meio de desenvolvimento das propostas. Somado a isso, é fundamental que os professores tenham a sua disposição um conjunto de orientações oficiais e materiais de referência que desenvolvam conteúdos a partir dessa perspectiva, podendo-se destacar, dado seu papel de orientador do desenvolvimento curricular (Chopin, 2004), o livro didático.

$\mathrm{O}$ ensino dos temas relacionados à saúde desde os anos iniciais do ensino fundamental, à medida que incorpore tais aportes, tem a potencialidade de propiciar aos alunos condições de compreender que as condições de saúde não são definidas apenas por aspectos naturais ou relacionadas ao acaso, sorte ou privilégio. A partir da compreensão da saúde como um direito e relacionada a uma gama bastante distinta de determinantes, crianças e jovens poderão posicionar-se criticamente frente às condições de vida a que estão submetidos, assim como as comunidades a que pertencem, e poderão enfrentar os possíveis fatores desfavoráveis à saúde visando, em última análise, à melhoria das condições de vida e de saúde, tanto no âmbito individual quanto no coletivo.

Entendidas a escola como local e a educação como prática social que, pelo menos em tese, se propõem a criar condições para que os alunos sejam capazes de se posicionar criticamente frente à realidade, as propostas para o ensino da saúde no ambiente escolar devem poder contribuir para a diminuição das iniquidades em saúde relacionadas às desigualdades de diversas ordens existentes no país, com vistas à melhoria das condições de vida dos indivíduos, grupos e comunidades. 


\section{NOTAS}

* Trabalho decorrente de Monteiro (2012).

${ }^{1}$ Dados os objetivos deste artigo, os PCN analisados são os referentes aos anos iniciais do ensino fundamental (primeiro ao quinto). Não são objeto de análise os parâmetros para as séries finais do ensino fundamental (atuais sexto ao nono anos) e para o ensino médio (PCNEM).

${ }^{2}$ A utilização da expressão "educação da saúde" é pertinentemente criticada por Mohr (2002), que afirma denotar um entendimento único da saúde, ou a existência de apenas um tipo de saúde considerado bom, "a saúde".

\section{REFERÊNCIAS}

ALMEIDA FILHO, Naomar de.

O que é saúde? Rio de Janeiro: Fiocruz. 2011.

ALMEIDA FILHO, Naomar de.

O conceito de saúde: o ponto-cego da epidemiologia? Revista Brasileira de Epidemiologia, v.3 n.1-3, p.4-20. 2000.

APPLE, Michael.

Repensando ideologia e currículo. In: Moreira, Antonio Flavio Barbosa; Silva, Tomás Tadeu da (Org.). Currículo, cultura e sociedade. São Paulo: Cortez. p.39-58. 2002.

ARROYO, Miguel G.

Currículo, território em disputa. Petrópolis: Vozes. 2011.

BAGNATO, Maria Helena.

O ensino da saúde nas escolas de $1^{\circ}$ grau. Próposições, v.1, n.1, p.53-59. 1990.

BRASIL.

Conselho Nacional de Educação. Câmara de Educação Básica. Resolução n.7/2010.

Fixa Diretrizes Curriculares Nacionais para o Ensino Fundamental de 9 (nove) anos. Brasília: Ministério da Educação. 2010a.

BRASIL.

Conselho Nacional de Educação. Câmara de Educação Básica. Parecer n.11/2010. Diretrizes Curriculares Nacionais para o Ensino Fundamental de 9 (nove) anos. Brasília: Ministério da Educação. 2010b.

BRASIL.

Presidência da República. Casa Civil. Subchefia para Assuntos Jurídicos. Decreto n.6.286, de 5 de dezembro de 2007. Institui o Programa Saúde na Escola - PSE, e dá outras providências. Disponível em: http://www.planalto.gov.br/ccivil_03/_ ato2007-2010/2007/decreto/d6286.htm. Acesso em: 28 ago. 2012. 2007.

BRASIL.

Conselho Nacional de Educação. Câmara de Educação Básica. Resolução CEB n.2/1998. Institui as Diretrizes Curriculares Nacionais para o Ensino Fundamental. Brasília: Ministério da Educação e do Desporto. 1998a.
BRASIL.

Conselho Nacional de Educação. Câmara de Educação Básica. Parecer CEB 04/98.

Diretrizes Curriculares Nacionais para o Ensino Fundamental. Brasília: Ministério da Educação e do Desporto. 1998b.

BRASIL.

Ministério da Educação. Secretaria de Educação Fundamental. Parâmetros Curriculares Nacionais: ciências naturais ( $1^{\mathrm{a}}$ a $4^{\mathrm{a}}$ séries). Brasília: MEC/ SEF. 1997a.

BRASIL.

Ministério da Educação. Secretaria de Educação Fundamental. Parâmetros Curriculares Nacionais: apresentação dos temas transversais, ética. Brasília: MEC/SEF. 1997b.

BRASIL.

Ministério da Educação. Secretaria de Educação Fundamental. Parâmetros Curriculares Nacionais: meio ambiente, saúde ( $1^{\mathrm{a}}$ a $4^{\mathrm{a}}$ séries). Brasília: MEC/SEF. 1997c.

BRASIL.

Lei n.9.394, de 20 de dezembro de 1996.

Estabelece as diretrizes e bases da educação nacional. Brasília. Disponível em: http://portal. mec.gov.br/seed/arquivos/pdf/tvescola/leis/ lein9394.pdf. Acesso em: 22 mar. 2013. 1996.

BRASIL.

Conselho Federal de Educação. Parecer 2.246/74. Ensino de $1^{\circ}$ e $2^{\circ}$ graus. Educação da Saúde e Programas de Saúde. Documenta 165. Brasília. 1974.

\section{BRASIL.}

Lei 5.692 de 11 de agosto de 1971. Fixa as Diretrizes e Bases para o ensino de $1^{\circ}$ e $2^{\circ}$ graus, e dá outras providências. Disponível em: http:// www.planalto.gov.br/ccivil_03/Leis/L5692.htm Acesso em: 27 abr. 2012. 1971.

BUSS, Paulo Marchiori; PELLEGRINI FILHO, Alberto.

A saúde e seus determinantes sociais. Physis, v.17, n.1, p.77-93. 2007.

CANGUILHEM, Georges. O normal e o patológico. Trad. de Maria Thereza 
Reding de Carvalho Barrocas. Rio de Janeiro: Forense Universitária. 2009.

CARNEIRO, Maria Helena da Silva; SANTOS, Widson Luiz Pereira dos; MOL, Gerson de Souza. Livro didático inovador e professores: uma tensão a ser vencida. Ensaio Pesquisa em Educação em Ciências, v.7, n.2, p.119-130. 2005.

CASTIEL, Luis David.

A saúde persecutória: os limites da responsabilidade. Rio de Janeiro: Fiocruz. 2007.

CHOPIN, Alain.

História dos livros e das edições didáticas.

Educação e Pesquisa, v.30, n.3, p.549-566. 2004.

COLLARES, Cecília Azevedo Lima; MOYSÉS, Maria Aparecida Affonso.

Educação ou Saúde? Educação X Saúde?

Educação e Saúde! Cadernos Cedes, n.15, p.7-16. 1985.

CZERESNIA, Dina.

O conceito de saúde e a diferença entre prevenção e promoção. In: Czeresnia, Dina; Freitas, Carlos Machado de. Promoção da saúde: debates, reflexões, tendências. Rio de Janeiro: Fiocruz. p.43-58. 2009.

DEJOURS, Christophe.

Por um novo conceito de saúde. Revista Brasileira de Saúde Ocupacional, v.54, n.14, p.7-11. 1986.

FERREIRA, Félix.

Noções da vida prática: livro de leitura para as escolas e de conhecimentos úteis para o povo. Rio de Janeiro: Alves \& C. 1894.

LIMA, Gerson Zanetta de.

Saúde Escolar - perspectivas de desenvolvimento. Cadernos Cedes, n.15, p.55-61. 1985.

LIMA, Maria Emília Caixeta de Castro; SILVA, Penha de Souza.

Critérios que professores de química apontam como orientadores da escolha do livro didático. Ensaio Pesquisa em Educação em Ciências, v.12, n.2, p.121-136. 2010.

MILANO, Mario.

Ciências físicas e naturais: higiene de acordo com o programa oficial. São Paulo: Monteiro Lobato. 1922.

MOHR, Adriana.

A natureza da educação em saúde no ensino fundamental e os professores de ciências. Tese (Doutorado) - Centro de Ciências da Educação, Universidade Federal de Santa Catarina, Florianópolis. 2002.

MONTEIRO, Paulo Henrique Nico.

A saúde nos livros didáticos no Brasil: concepções e tendências nos anos iniciais do Ensino Fundamental. Tese (Doutorado em educação)
- Faculdade de Educação, Universidade de São Paulo, São Paulo. 2012.

MOREIRA, Antonio Flavio Barbosa; SILVA, Tomás Tadeu da.

Sociologia e teoria crítica do currículo: uma introdução. In: Moreira, Antonio Flavio Barbosa; Silva, Tomás Tadeu da (Org.). Currículo, cultura e sociedade. São Paulo: Cortez. p.7-38. 2002.

MOURA, Erly Catarina de.

Ensino da saúde no currículo - subtema nutrição. Ciências e Cultura, v.42, p.283-287. 1980.

NUNES, Everardo.

Saúde coletiva: história e paradigmas. Interface, v.2, n.3, p.107-116. 1998.

SACRISTÁN, Jurjo Gimeno.

O currículo: uma reflexão sobre a prática. Trad. de E.F.F. Rosa. Porto Alegre: ArtMed. 1998.

SAVIANI, Demerval.

História das ideias pedagógicas no Brasil.

Campinas: Autores Associados. 2008.

SAVIANI, Demerval.

Escola e democracia: teorias da educação, curvatura da vara, onze teses sobre educação e política. (Coleção Polêmicas do Nosso Tempo; v.5). Campinas: Autores Associados. 1995.

SCHALL, Virginia Torres et al.

Avaliação dos conhecimentos sobre doenças parasitárias entre os professores e alunos do $1^{\circ}$ grau. Ciência e Cultura, v.39, supl., p.160-172. 1987.

SCHALL, Virgínia Torres; STRUCHINER, Miriam. Educação em saúde: novas perspectivas. Cadernos de Saúde Pública, v.15, supl.2, p.S4-S6. 1999.

SILVA, Tomás Tadeu da.

Documentos de identidade: uma introdução às teorias do currículo. Belo Horizonte: Autêntica. 2003.

WESTPHAL, Marcia.

Promoção da saúde e prevenção de doenças. In: Campos, Gastão Wagner de Souza et al. (Org.). Tratado de Saúde Coletiva. São Paulo: Hucitec; Rio de Janeiro: Fiocruz. p.635-667. 2006.

WHO.

World Health Organization. Milestones in Health Promotion: statements from Global Conferences. Disponível em: http://www. who.int/healthpromotion/Milestones_Health_ Promotion_05022010.pdf. Acesso em: 21 mar. 2013. 2009.

WHO.

World Health Organization. Health Promotion Glossary. Génève: WHO/HPR/HEP. Disponível em: http://www.who.int/hpr/NPH/docs/hp_ glossary_en.pdf. Acesso em: 16 maio 2012. 1998. 